\title{
Enzymatic Activity of the Mycelium Compared with Oospore Development During Infection of Pea Roots by Aphanomyces euteiches
}

\author{
Rasmus Kjøller and Søren Rosendahl
}

Department of Mycology, Botanical Institute, University of Copenhagen, Øster Farimagsgade 2D, 1353 Copenhagen K, Denmark. Accepted for publication 4 June 1998.

\begin{abstract}
Kjøller, R., and Rosendahl, S. 1998. Enzymatic activity of the mycelium compared with oospore development during infection of pea roots by Aphanomyces euteiches. Phytopathology 88:992-996.

To describe the disease cycle of the root pathogen Aphanomyces euteiches, enzymatic activity in the mycelium was compared with the development of oospores in pea roots. Plants were inoculated with two zoospore concentrations to achieve different disease levels. Hyphae were stained for fungal alkaline phosphatase activity in the roots. Additionally, enzyme activity was measured after electrophoresis of an A. euteiches-specific

glucose-6-phosphate isozyme. Development of oospores in the roots was measured after staining the oospores with trypan blue. In plants inoculated with the higher zoospore concentration, the enzymatic activity of the pathogen mycelium peaked 10 to 14 days after inoculation, when oospore formation was initiated. Oospore formation was associated with a gradual increase in disease symptoms. At the last harvest, plants inoculated with the higher zoospore concentration had died. In these plants, oospores were found in $90 \%$ of the root length, while the enzymatic activity of the mycelium was low. This suggests that the pathogen mycelium is only active on living plants and does not grow saprophytically on dead plant material.
\end{abstract}

Aphanomyces euteiches is a destructive pathogen in pea-growing areas all over the world $(6,11)$. The life cycle of this oomycete includes germination of oospores in the soil, producing zoospores that encyst on the root surface. After infection, mycelium grows through the root cortex and, during the later stages of pathogenesis, oospores are formed. Oospores are released into the soil as the roots decay, and they can persist as an inoculum source for as long as 10 years $(9,11)$. No fungicides or resistant pea lines are commercially available for the control of this pathogen, and it can only be controlled by avoiding infested fields $(1,9)$.

To develop new control strategies, it is necessary to provide more information on pathogenesis. Several studies have described the attraction and encystment of zoospores and germination of cysts in the presence of roots $(2,3)$, but the further growth of the pathogen in the root tissue is not thoroughly described. The degree of root infection by $A$. euteiches is usually evaluated by the severity of symptoms on the host plant (10). This indirect method may not directly reflect the amount of fungal colonization, and similar symptoms may also be caused by several fungal root pathogens (11). Other studies have directly measured colonization by quantifying oospores in the root tissue $(8,13)$ or by measuring the reaction between infected roots and an Aphanomyces-specific polyclonal antiserum (6). These methods will not differentiate between active and inactive structures of the pathogen, which is important, as the pathogen is only likely to be susceptible to control agents in the active state. Recently, the activity of $A$. euteiches-specific enzymes has been quantified after electrophoresis of root extracts from diseased plants $(4,5)$. In these studies, no correlation was found between fungal enzymatic activity and percent infected root length with oospores in the late stage of infection. This suggested that the measured enzymatic activity originated from fungal mycelium and not from oospores, but so far it has not been possible to stain the mycelium of $A$. euteiches in the roots.

Corresponding author: S. Rosendahl; E-mail address: soerenr@bot.ku.dk

Publication no. P-1998-0721-01R

(C) 1998 The American Phytopathological Society
Enzymatic activity of fungal hyphae within plant tissue can be visualized directly with histochemical staining of hyphae. We used this approach to visualize possible enzymatic activity of $A$. euteiches mycelium in roots of pea. To reflect the general activity of the pathogen, we used the enzyme alkaline phosphatase (ALP), which is involved in the primary metabolism. ALP has the advantage that plant roots do not express this enzyme, which makes it easier to detect the enzymatically active pathogen inside the root tissue (17).

In the current study, we describe a method to visualize active mycelium of A. euteiches in pea roots by staining for ALP activity. We used this method to compare the enzymatic activity of the mycelium of $A$. euteiches with the development of oospores in roots and to relate this to the development of disease symptoms in the plants. A more precise description of the activity pattern of the pathogen during the infection may allow more refined control strategies to be developed in the future.

\section{MATERIALS AND METHODS}

Plant material. Seeds of Pisum sativum L. (cv. Ping-Pong) were surface-sterilized for $2 \mathrm{~min}$ in $70 \%$ ethanol, rinsed in distilled water, and pregerminated for 7 days on moist vermiculite at $24^{\circ} \mathrm{C}$. Seedlings were transplanted into pots with $50 \mathrm{~g}$ of sterilized vermiculite (two seedlings per pot), and the pots were watered to the same weight with a commercial fertilizer (NPK, 7-1-5) solution every second day. Plants were grown in a greenhouse between February and March with supplementary light for $16 \mathrm{~h} \mathrm{day}^{-1}$ and a minimum temperature of $18^{\circ} \mathrm{C}$. The pots were rotated weekly in order to obtain a randomized design.

A. euteiches. A strain of A. euteiches Drechs. (ATCC 201684) isolated from pea in Denmark was maintained on corn meal agar (CMA) (Difco Laboratories, Detroit) at $4{ }^{\circ} \mathrm{C}$. Zoospore inoculum was made by transferring approximately $105 \times 5$-mm disks from the edge of a CMA culture to maltose peptone broth $(1 \mathrm{~g}$ of maltose and $3 \mathrm{~g}$ of peptone in 1 liter of distilled water) in petri dishes. After incubating for 5 days at $24^{\circ} \mathrm{C}$, the mycelium was washed in autoclaved lake water (Botanical Garden, Copenhagen) for $1 \mathrm{~h}$, the wash water was discarded, and the mycelium was left for $24 \mathrm{~h}$ in fresh autoclaved lake water. The zoospore suspension was diluted to ob- 
tain two inoculum levels: 500 and 500,000 zoospores per pot. The plants were inoculated 10 days after transplanting by applying $10 \mathrm{ml}$ of zoospore suspension to each pot at the stem base of the plants. Control plants received the same amount of sterile lake water. Twenty pots of each treatment were inoculated or left uninoculated.

Harvest and histochemical staining of hyphae. Four plants from each treatment were harvested at 6, 10, 14, 20, and 27 days after inoculation with $A$. euteiches. The roots from each pot were treated independently. The roots were rinsed with cold tap water and kept on ice until further processed. Plants were evaluated for disease severity using five disease severity index classes: $0=$ no symptoms; 1 = honey-colored discoloration of roots, but no symptoms on epicotyl and shoot; 2 = roots and epicotyl dark honey-colored, but no symptoms on shoot; 3 = roots with necrosis and shoot partly wilted; and 4 = shoot totally wilted. Shoots were cut off below the cotyledons and shoot dry weight determined after drying to constant weight at $70^{\circ} \mathrm{C}$. The roots from each pot were blotted dry, weighed, and then suspended in 1 liter of cold tap water, mixed together, and then collected again on a $100-\mu \mathrm{m}$ sieve. The collected roots were divided into three fractions. One fraction was cleared in $10 \% \mathrm{KOH}$ and stained for oospores with trypan blue $(12,13)$. A second root fraction was stained for fungal ALP (EC 3.1.3.1)

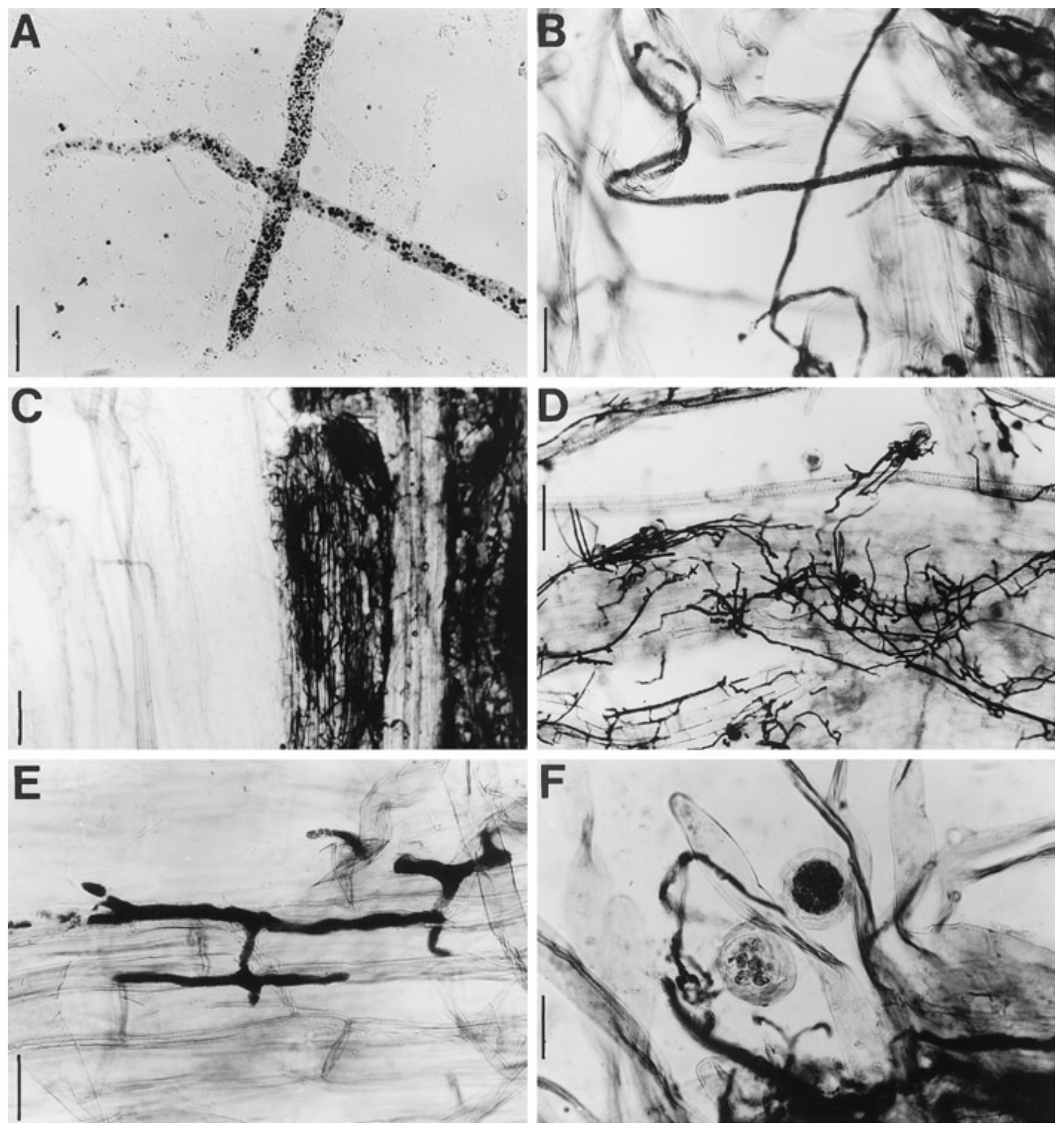

Fig. 1. A, Alkaline phosphatase (ALP)-stained hyphae of Aphanomyces euteiches grown in vitro. B through F, All are from squashed root segments: B, ALPstained hyphae; C, noncolonized root segment (left) and colonized root segment (right); D, hyphae spreading on the root surface; E, ALP-stained hyphae growing between root cortex cells; and $\mathbf{F}$, young oogonia with undifferentiated content showing ALP activity (right) and oogonia with differentiated oospheres showing no ALP activity (left). Bars: A, B, E, and F, $25 \mu \mathrm{m} ; \mathbf{C}, 200 \mu \mathrm{m}$; and $\mathbf{D}, 100 \mu \mathrm{m}$. 
activity as described for arbuscular mycorrhizal fungi by Tisserant et al. (17). A third root fraction was blotted dry, weighed, and submitted to protein extraction (as described below).

The roots stained for fungal ALP activity were preincubated in a digestion medium as described by Tisserant et al. (17). The roots were stained overnight, cleared in 3\% sodium hypochlorite for $20 \mathrm{~min}$, and stored in lactoglycerol $(800 \mathrm{ml}$ of lactic acid, $100 \mathrm{ml}$ of glycerol, and $100 \mathrm{ml}$ of distilled water) at $4^{\circ} \mathrm{C}$. Controls for the ALP reaction were made by incubating roots in the reaction medium in the presence of $20 \mathrm{mM} \mathrm{KCN}$ or $\mathrm{NaF}$ (inhibitors of alkaline and acid phosphatases, respectively), without substrate or in $0.1 \mathrm{M}$ acetate buffer at pH 5 (staining of acid phosphatases) (17). For additional control of the ALP reaction, mycelium of A. euteiches grown in liquid culture was stained for ALP. The fungus was grown on petri dishes with glucose peptone broth $(5 \mathrm{~g}$ of glucose and $25 \mathrm{~g}$ of peptone in 1 liter of distilled water) for 9 days at $24^{\circ} \mathrm{C}$, and the mycelial mats were washed with distilled water and stained for ALP activity with or without $20 \mathrm{mM} \mathrm{KCN}$ in the reaction buffer.

Quantification of A. euteiches infection. The stained roots were mounted on microscope slides in polyvinyl lactoglycerol and examined at $\times 100$ magnification for percent root length infected. The roots were scored for presence or absence of trypan blue-stained oospores or ALP-stained hyphae at 200 intersections between the roots and a hairline in the eyepiece (7).

Protein extraction. For identifying A. euteiches glucose-6phosphate dehydrogenase (EC 1.1.1.49) (Gd) activity in the infected roots, proteins were extracted from the third root fraction as described by Kjøller and Rosendahl $(4,5)$ with an extraction buffer as described by Rosendahl and Sen (14).

Electrophoresis and activity staining of gels. Electrophoresis was carried out as described by Kjøller and Rosendahl $(4,5)$. The gels were stained for Gd as described by Soltis and Soltis (16). Fungal Gd bands were identified by comparing pure culture mycelium extracts of A. euteiches with infected and noninfected roots as described by Kjøller and Rosendahl $(4,5)$. The gels were scanned on a AGFA Studioscan 2 (Agfa-Gevaert, Mortsel, Belgium) and analyzed with the Phoretix 1D version 3.0 software (Phoretix International, Newcastle, United Kingdom). The intensity of each band was expressed as the sum of pixels in each band.

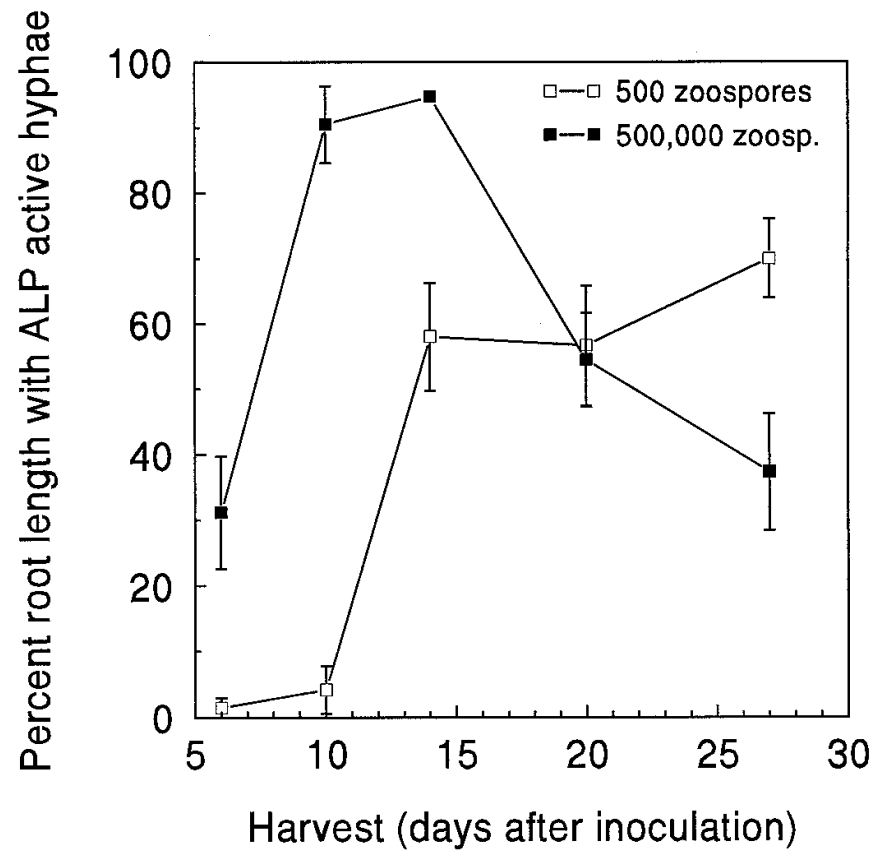

Fig. 2. Percent root length with alkaline phosphatase-active hyphae in plants inoculated with 500 and 500,000 zoospores per pot. Each point is the mean of four replicates, bars indicate standard errors.

\section{RESULTS}

ALP activity could be visualized as a black precipitate within hyphal compartments of $A$. euteiches grown in vitro and also in hyphae growing in roots (Fig. 1A and B). The strong ALP reaction within the hyphae made it easy to discriminate between colonized and noncolonized roots (Fig. 1C). The stained hyphae associated with infected roots was found both on the root surface and also between the root cortex cells (Fig. 1D and E). Young, undifferentiated oogonia showed ALP activity, while no activity was found in oogonia with differentiated oospheres or in mature oospores (Fig. 1F). Incubation of the mycelium grown in vitro with $20 \mathrm{mM}$ $\mathrm{KCN}$ in the reaction buffer completely inhibited the ALP reaction, whereas $20 \mathrm{mM} \mathrm{KCN}$ or $20 \mathrm{mM} \mathrm{NaF}$ in the reaction buffer did not inhibit the staining of the hyphae in the roots. No stained hyphae were seen in A. euteiches-infected root samples that had been incubated without substrate or when the hyphae were incubated at $\mathrm{pH} 5$.

A rapid increase in the percent colonized root length was seen between 5 and 10 days after inoculation in plants inoculated with the higher inoculum level. A similar rapid increase could be seen in plants inoculated with the lower inoculum level, but the increase was delayed until 10 and 14 days after inoculation. Ten days after inoculation, almost the entire root system was colonized by $A$. euteiches when inoculated with the higher inoculum level (Fig. 2). In plants inoculated with the higher inoculum level, the percent root length with ALP active hyphae was highest 14 days after inoculation and declined at each successive harvest. No such decline was seen in plants inoculated with the lower inoculum level, in which the colonization continued to increase between 14 and 25 days after inoculation (Fig. 2). Activity of A. euteiches-specific Gd extracted from the roots followed closely the pattern observed for percent root length with ALP-active hyphae (Fig. 3).

Oospore formation was initiated 6 days after inoculation and, in plants inoculated with the higher inoculum level, reached a level of $90 \%$ of the root length at the last harvest (Fig. 4). Oospores were first seen 10 days after inoculation in plants inoculated with the lower inoculum level, and oospore formation in these plants stayed at a low level until 20 days after inoculation. Between 20 and 25 days after inoculation, a steep increase in percent infection with oospores was seen in plants inoculated with the lower inoculum level (Fig. 4).

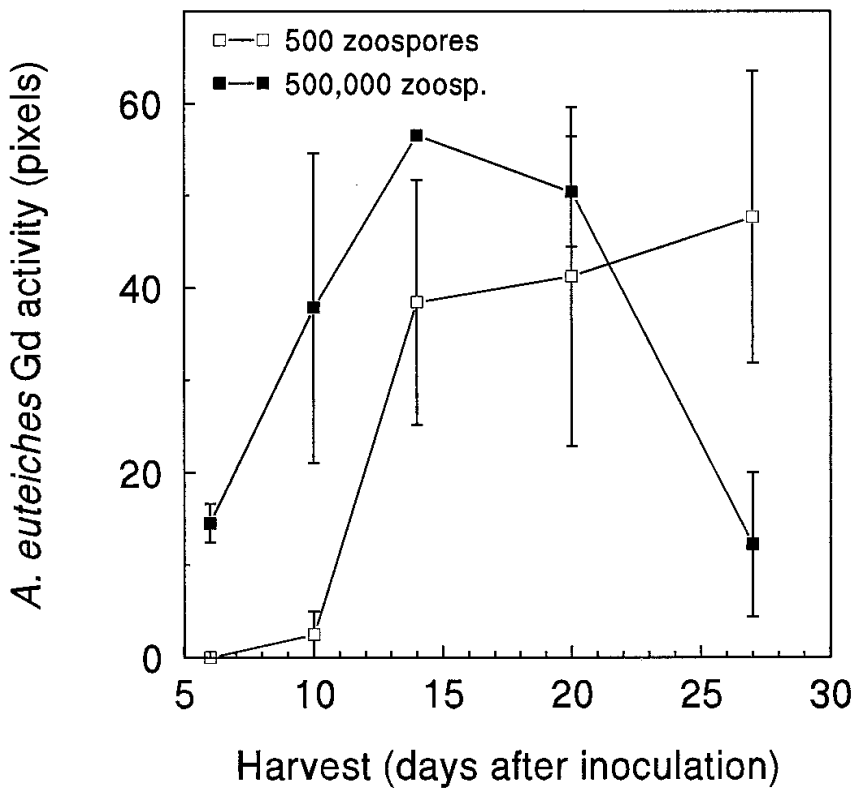

Fig. 3. Aphanomyces euteiches glucose-6-phosphate activity in plants inoculated with 500 and 500,000 zoospores per pot. Each point is the mean of four replicates, bars indicate standard errors. 
Plant disease symptoms increased gradually during the experiment and faster in plants inoculated with the higher inoculum level. These plants had wilted completely at the last harvest (Fig. 5). There were significantly lower shoot and root dry weight of plants inoculated with the high inoculum level in comparison to control plants at the last three harvests (Table 1). The effect of the lower inoculum level with respect to dry weights was only seen at the last harvest.

\section{DISCUSSION}

In plants inoculated with the higher inoculum level, hyphae of A. euteiches were only active during a limited period after infection of the pea roots. The period of active mycelium was followed by development of oospores, which, in the later phase, was inversely related to the activity of the hyphae. This apparent decrease in vegetative growth and induction of sexual reproduction is interesting, although the reason for this change is not known.

Earlier results suggested that $A$. euteiches does not survive by its saprophytic ability (15) and that plants weakened by A. euteiches in the field often are killed by secondary infection (e.g., Fusarium species) (9). This agrees with the results of the current study, in which the pathogen only showed enzymatic activity while the host was alive. Based on these results, A. euteiches should be regarded as a biotrophic pathogen.

The short, metabolically active phase of the pathogen during infection may explain why it is difficult to control the organism with field-sprayed chemicals. Fungicides are often inhibitors of metabolic pathways, but, by the time disease symptoms become visible on the above-ground parts of the host, the fungus is already dormant and is no longer susceptible to fungicides.

Hyphae of A. euteiches can be visualized by histochemical staining for ALP activity, a method that previously has been used to stain arbuscular mycorrhizal fungi in roots (17). The percent infection with ALP-active hyphae followed the same pattern as the $A$. euteiches Gd activity, which previously has been used to quantify the active biomass of $A$. euteiches in roots $(4,5)$. There was no staining of mycelium when substrate was omitted or at acid $\mathrm{pH}$. The nature of the reaction was further characterized by inhibiting the reaction with cyanide. The lack of inhibition of the reaction with cyanide in the roots was probably due to insufficient penetration of the cyanide, since the activity in hyphae grown in liquid culture

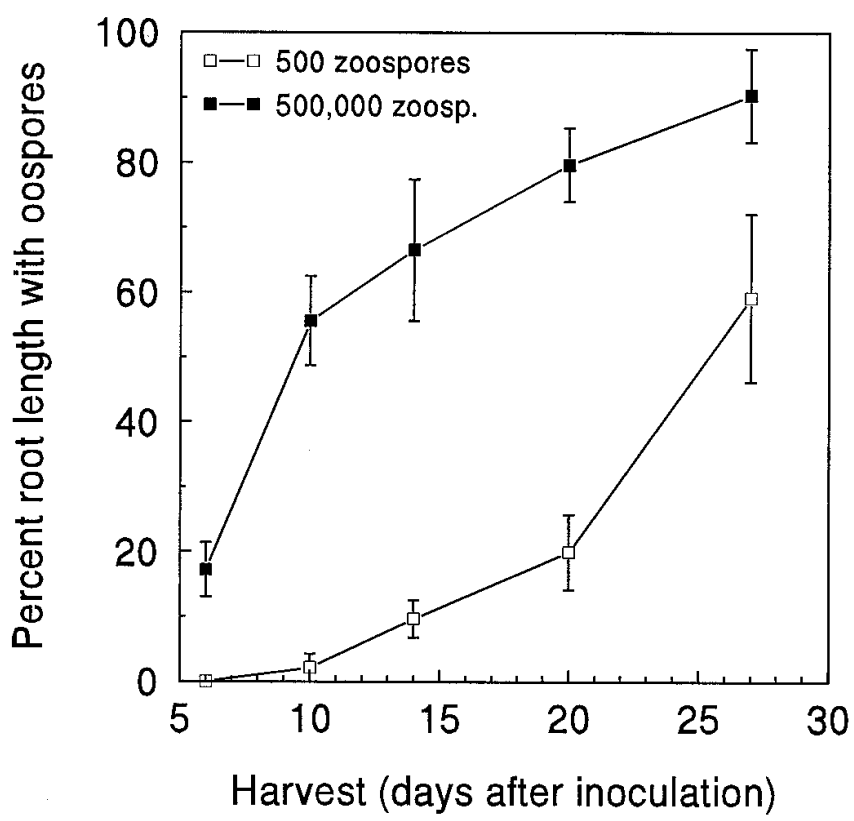

Fig. 4. Percent root length with Aphanomyces euteiches oospores in plants inoculated with 500 and 500,000 zoospores per pot. Each point is the mean of four replicates, bars indicate standard errors. was completely inhibited by cyanide. More detailed investigations are needed to further characterize this ALP.

Staining for ALP offers a fast and easy way to visualize living mycelium of $A$. euteiches in roots and could be useful in evaluating various treatments on the vitality of this and other root pathogens. In studies with more than one pathogen present in the root system, care must be taken if both pathogens stain for ALP activity. In such studies, the electrophoretic-enzymatic technique is more appropriate, as it permits differentiation between the different organisms involved.

The current study shows that infection of pea roots by $A$. euteiches is initiated by a rapid colonization of the root system by metabolically active hyphae followed by oospore formation and a decrease in activity of the mycelium. This result suggests that chemical or biological control of the pathogen in the roots will continue to be difficult because of the relatively short period with metabolically active hyphae.

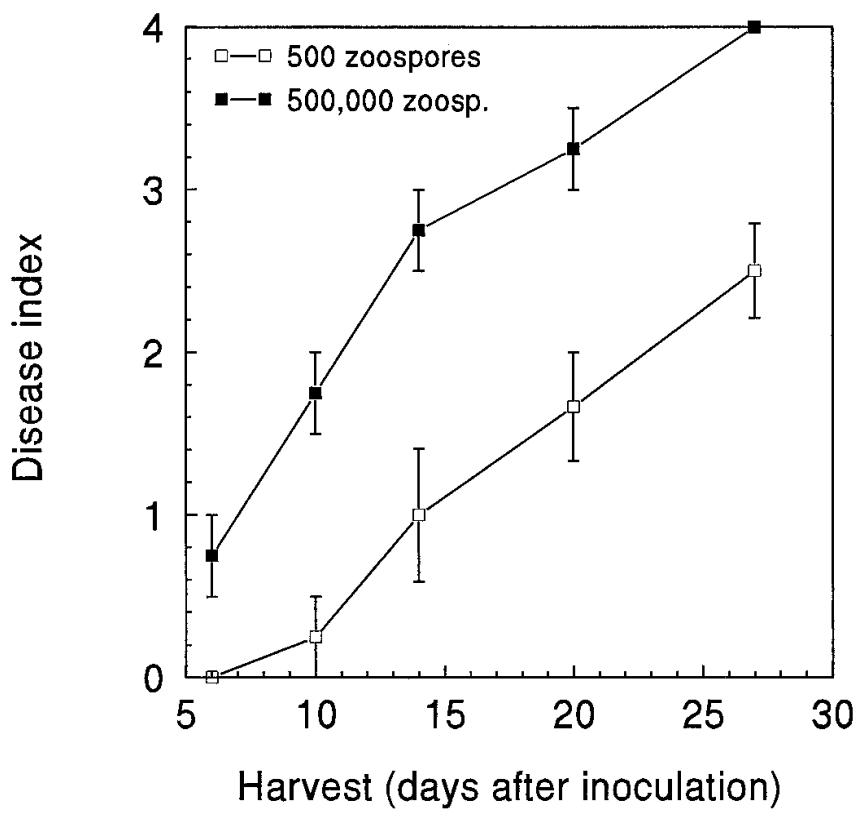

Fig. 5. Average symptom index: $0=$ no symptoms; 1 = honey-colored discoloration of roots, but no symptoms on epicotyl and shoot; $2=$ roots and epicotyl dark honey-colored, but no symptoms on shoot; $3=$ roots with necrosis and shoot partly wilted; and $4=$ shoot completely wilted, plant dead. Each point is the mean of four replicates, bars indicate standard errors.

TABLE 1. Effect of inoculation with 500 and 500,000 zoospores of Aphanomyces euteiches on dry weight of pea plants

\begin{tabular}{lrrr}
\hline \multirow{2}{*}{$\begin{array}{l}\text { Harvest } \\
\text { (days after inoculation) }\end{array}$} & $\begin{array}{c}\text { Zoospore inoculum } \\
\text { (number) }\end{array}$ & \multicolumn{2}{c}{ Dry weight $(\mathrm{mg})^{\mathrm{z}}$} \\
\cline { 3 - 4 } 6 & 0 & $199 \mathrm{a}$ & $94 \mathrm{a}$ \\
& 500 & $224 \mathrm{a}$ & $73 \mathrm{a}$ \\
& 500,000 & $214 \mathrm{a}$ & $112 \mathrm{a}$ \\
10 & 0 & $297 \mathrm{a}$ & $128 \mathrm{a}$ \\
& 500 & $338 \mathrm{a}$ & $127 \mathrm{a}$ \\
& 500,000 & $256 \mathrm{a}$ & $107 \mathrm{a}$ \\
14 & 0 & $562 \mathrm{a}$ & $145 \mathrm{a}$ \\
& 500 & $468 \mathrm{a}$ & $136 \mathrm{a}$ \\
& 500,000 & $237 \mathrm{~b}$ & $85 \mathrm{~b}$ \\
20 & 0 & $807 \mathrm{a}$ & $199 \mathrm{a}$ \\
& 500 & $691 \mathrm{a}$ & $179 \mathrm{a}$ \\
& 500,000 & $272 \mathrm{~b}$ & $89 \mathrm{~b}$ \\
27 & 0 & $1,846 \mathrm{a}$ & $285 \mathrm{a}$ \\
& 500 & $792 \mathrm{~b}$ & $149 \mathrm{~b}$ \\
& 500,000 & $259 \mathrm{~b}$ & $57 \mathrm{c}$ \\
\hline
\end{tabular}

${ }^{z}$ Data are means of four replicates. Data followed by the same letter within each harvest are not statistically different (Student-Newman-Keuls test, $P=0.05$ ). 


\section{ACKNOWLEDGMENTS}

This research was supported by a grant from the Danish Ministry of Environment. We wish to thank K. Kristiansen and E. Meier Andersen for technical assistance and A. Gargas for critically reading the manuscript.

\section{LITERATURE CITED}

1. Chan, M. K. Y., and Close, R. C. 1987. Aphanomyces root rot of peas. 1. Evaluation of methods for assessing inoculum density of Aphanomyces euteiches in soil. N.Z. J. Agric. Res. 30:213-217.

2. Cunningham, J. L., and Hagedorn, D. J. 1962. Attraction of Aphanomyces euteiches zoospores to pea and other plant roots. Phytopathology 52: 616-618.

3. Deacon, J. W., and Saxena, G. 1998. Germination triggers of zoospore cysts of Aphanomyces euteiches and Phytophthora parasitica. Mycol. Res. 102:33-41.

4. Kjøller, R., and Rosendahl, S. 1996. The presence of the arbuscular mycorrhizal fungus Glomus intraradices influences enzymatic activity of the root pathogen Aphanomyces euteiches in pea roots. Mycorrhiza 6:487-491.

5. Kjøller, R., and Rosendahl, S. 1997. Polyacrylamide gel electrophoresis (PAGE) and densitometric measurement of enzyme activity of the pea root pathogen Aphanomyces euteiches in pea roots. J. Phytopathol. 145: 253-256.

6. Kraft, J. M., and Boge, W. L. 1994. Development of an antiserum to quantify Aphanomyces euteiches in resistant pea lines. Plant Dis. 78:179-183.

7. McGonigle, T. P., Miller, M. H., Evans, D. G., Fairchild, G. L., and Swam, J. A. 1990. A new method which gives an objective measure of colonization of roots by vesicular-arbuscular mycorrhizal fungi. New Phytol.
115:495-501.

8. Morrison, R. H., Johnson, J. K., King, T. H., and Davis, D. 1971. An evaluation of the excised root tip method for determining the resistance of Pisum sativum to Aphanomyces euteiches. J. Am. Soc. Hortic. Sci. 96:616-619.

9. Papavizas, G. C., and Ayers, W. A. 1974. Aphanomyces species and their root rot diseases in pea and sugarbeet. U.S. Dep. Agric. Res. Tech. Bull. 1485.

10. Parke, J. L., and Grau, C. R. 1992. Aphanomyces. Pages 27-30 in: Methods for Research on Soilborne Phytopathogenic Fungi. L. L. Singleton, J. D. Mihail, and C. M. Rush, eds. The American Phytopathological Society, St. Paul, MN.

11. Pfender, W. F. 1989. Aphanomyces root rot. Pages 25-28 in: Compendium of Pea Diseases. D. J. Hagedorn, ed. The American Phytopathological Society, St. Paul, MN.

12. Phillips, J. M., and Hayman, D. S. 1970. Improved procedures for clearing roots and staining parasitic and vesicular-arbuscular mycorrhizal fungi for rapid assessment of infection. Trans. Br. Mycol. Soc. 55:158-160.

13. Rosendahl, S. 1985. Interaction between the vesicular-arbuscular mycorrhizal fungus Glomus fasciculatum and Aphanomyces euteiches. Phytopathol. Z. 114:31-40.

14. Rosendahl, S., and Sen, R. 1992. Isozyme analysis of mycorrhizal fungi and their mycorrhiza. Pages 169-194 in: Methods in Microbiology, Vol. 24. A. K. Varma, D. J. Read, and J. R. Norris, eds. Academic Press, London.

15. Sherwood, R. T., and Hagedorn, D. J. 1962. Studies on the biology of Aphanomyces euteiches. Phytopathology 52:150-154.

16. Soltis, D. E., and Soltis, T. S. 1989. Isozymes in Plant Pathology. Chapman and Hall, London.

17. Tisserant, B., Gianinazzi-Pearson, V., Gianinazzi, S., and Gollotte, A. 1993. In planta histochemical staining of fungal alkaline phosphatase activity for analysis of efficient arbuscular mycorrhizal infections. Mycol. Res. 97:245-250. 